\title{
Review of Vortices in Wildland Fire
}

\author{
Jason M. Forthofer ${ }^{1}$ and Scott L. Goodrick ${ }^{2}$ \\ ${ }^{1}$ Rocky Mountain Research Station, USDA Forest Service, 5775 W US Highway 10, Missoula, MT 59808, USA \\ ${ }^{2}$ Southern Research Station, USDA Forest Service, 320 Green Street, Athens, GA 30602, USA \\ Correspondence should be addressed to Jason M. Forthofer, jaforthofer@fs.fed.us
}

Received 30 December 2010; Accepted 15 March 2011

Academic Editor: D. Morvan

Copyright (C 2011 J. M. Forthofer and S. L. Goodrick. This is an open access article distributed under the Creative Commons Attribution License, which permits unrestricted use, distribution, and reproduction in any medium, provided the original work is properly cited.

\begin{abstract}
Vortices are almost always present in the wildland fire environment and can sometimes interact with the fire in unpredictable ways, causing extreme fire behavior and safety concerns. In this paper, the current state of knowledge of the interaction of wildland fire and vortices is examined and reviewed. A basic introduction to vorticity is given, and the two common vortex forms in wildland fire are analyzed: fire whirls and horizontal roll vortices. Attention is given to mechanisms of formation and growth and how this information can be used by firefighters.
\end{abstract}

\section{Introduction}

Large fire whirls are often one of the more spectacular aspects of fire behavior. Flames flow across the ground like water feeding into the base of the vortex, the lowest thousand feet of which often takes on an orange glow from combusting gases rising within the vortex core. Burning debris lofted within the vortex can lead to a scattering of spot fires some distance from the main fire. With their sudden formation, erratic movement, and often sudden dissipation, fire whirls are a good example of extreme fire behavior. However, other forms of vortices are actually quite common on wildland fires and receive less attention despite their potential to dramatically alter fire behavior.

This paper is designed to provide a better understanding of vortices associated with wildland fires, both fire whirls, and horizontal roll vortices. A key point will be providing a basic understanding of what aspects of the fire environment contribute to the development and growth of these vortices. The next section supplies a brief introduction to vorticity, a measure of the atmosphere's tendency to spin or rotate about some axis. With this basic understanding of vorticity, we will examine the common vortex forms described in the fire behavior literature, fire whirls, and horizontal roll vortices.

\section{Vorticity Basics}

Simply stated, vorticity is the measure of spin about an axis. That axis can be vertical, as in the case of a fire whirl, or horizontal for a roll vortex, or somewhere in between. Mathematically, vorticity is a vector quantity (it has both magnitude and directional information) that is defined as the curl of the wind field:

$$
\vec{\omega}=\nabla x \vec{V}
$$

or in component form:

$$
\vec{\omega}=\left(\frac{\partial w}{\partial y}-\frac{\partial v}{\partial z}\right) \hat{i}+\left(\frac{\partial u}{\partial z}-\frac{\partial w}{\partial x}\right) \hat{j}+\left(\frac{\partial v}{\partial x}-\frac{\partial u}{\partial y}\right) \hat{k} .
$$

As a simple hypothetical example, take a vertical crosssection through a fire with no ambient horizontal winds (Figure 1). The vertical winds near the ground can be characterized by a strong updraft over the fire and descending air outside of the fire area. The change in the vertical velocity along the $x$-axis imparts rotation to the flow field about the $y$-axis. Note that this does not describe how vorticity is generated, but rather just illustrates the definition. The complete vorticity equation can be derived by applying (1) 


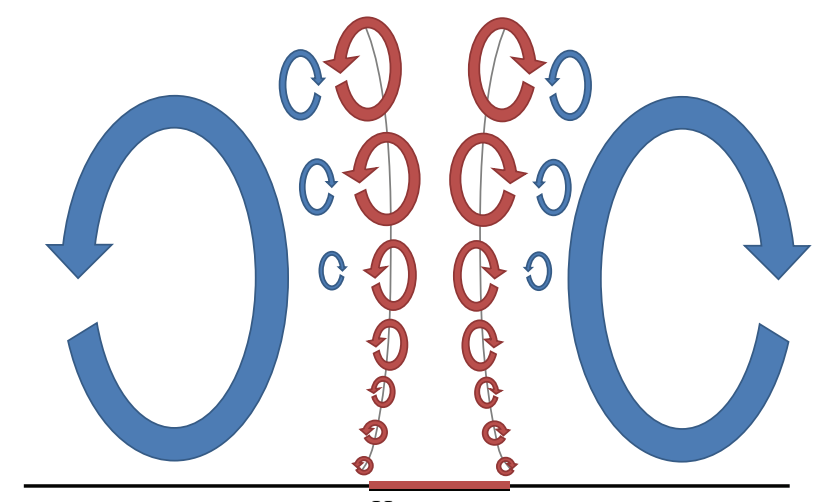

Heat source

FIGURE 1: Vertical cross-section through idealized fire illustrating occurrence of vortices due to horizontal gradient of vertical motion produced by buoyancy from the fire.

to the Navier-Stokes equations that describe fluid motions to get

$$
\begin{aligned}
\frac{\partial \vec{\omega}}{\partial t}+(\vec{V} \cdot \vec{\nabla}) \vec{\omega}= & (\vec{\omega} \cdot \vec{\nabla}) \vec{V}-\vec{\omega}(\vec{\nabla} \cdot \vec{V})+\frac{1}{\rho^{2}} \vec{\nabla} \rho \times \vec{\nabla} p \\
& +\vec{\nabla} \times\left(\frac{\vec{\nabla} \cdot \underline{\tau}}{\rho}\right)+\vec{\nabla} \times \vec{B} .
\end{aligned}
$$

The first term on the left-hand side of (3) is the time rate of change of vorticity at a point. All of the remaining terms in the equation describe processes by which the vorticity at a point is changed. The second term on the left-hand side is the advection, or transport, of vorticity by the wind. Thus vorticity generated in one place can impact another location.

The right-hand side of (3) begins with the tilting term, $(\vec{\omega} \cdot \vec{\nabla}) \vec{V}$, that describes how velocity gradients can transform horizontal vorticity into vertical vorticity and vice-versa. The second term on the right hand side, $\vec{\omega}(\vec{\nabla} \cdot \vec{V})$, describes how flow convergence (divergence) stretches (compresses) vortices and increases (decreases) the magnitude of the vorticity. Note that these tilting and stretching terms can only enhance the vorticity already present in the flow; they cannot generate new vorticity. The solenoidal or baroclinic term is the third term on the right hand side of (3), $\left(1 / \rho^{2}\right) \vec{\nabla} \rho \times \vec{\nabla} p$. This term generates vorticity in cases where the gradients in pressure and density are not parallel. In the case of a fire, rapid heating develops a horizontal temperature gradient that is not aligned with the vertical static pressure gradient. This misalignment of the vertical pressure gradient and horizontal thermal gradient leads to rotational motions to mix warm and cold fluid in an attempt to restore balance.

The fourth term in $(3), \vec{\nabla} \times((\vec{\nabla} \cdot \underline{\tau}) / \rho)$, provides for the generation of vorticity due to viscous shear stress. Wind shear induced by surface drag is a source of vorticity; therefore, if the wind is blowing at the earth's surface, horizontal vorticity is being generated. The final term in (3), $\vec{\nabla} \times \vec{B}$, represents changes in vorticity due to body forces such as gravity acting on the fluid.
In summary, the vorticity at any location changes due to the transport of vorticity from one place to another, the tilting of vorticity from one axis to another, the stretching and intensifying of vortices by convergence, or by the generation of vorticity through buoyancy and/or wind shear.

\section{Fire Whirls}

Fire whirls are vertically oriented, intensely rotating columns of gas found in or near fires. They have been observed in wildland, urban, and oil spill fires and volcanic eruptions. Dynamically they are closely related to other swirling atmospheric phenomena such as dust devils, waterspouts, and tornadoes [1]. Fire whirls have also been called fire devils, fire tornadoes, and even firenadoes. They are usually visually observable because of the presence of flame, smoke, ash, and/or other debris. The definition of a fire whirl used here includes those whirls caused by the buoyancy of a fire but with no inner core of flame. Fire whirls range in size from less than 1 meter in diameter and velocities less than $10 \mathrm{~m} \mathrm{~s}^{-1}$ up to possibly 3 kilometers in diameter and winds greater than $50 \mathrm{~m} \mathrm{~s}^{-1}$ [2]. The smaller fire whirls are fairly common on wildland fires, while the larger whirls are less common. All fire whirls, especially the larger ones, represent a considerable safety hazard to fire fighters through increased fire intensity, spotting, erratic spread rate and direction, and wind damage [3].

Several extremely large fire whirls have been reported in urban fires that illustrate their potentially destructive nature. In 1871, the Great Chicago Fire generated whirlwinds that lifted and transported burning planks 600 meters ahead of the main fire, which contributed greatly to the spread and destruction of the fire [4]. On the same day, a fire in Peshtigo, Wisconsin generated a whirl that was strong enough to lift a house off its foundations [5]. Hissong [6] also reported a whirl strong enough to move a house. This whirl was one of many that formed during a large oil storage facility fire. The whirl separated from the fire and moved 1,000 meters downwind, lifted the small house, and moved it 45 meters killing the 2 residents inside. A much more devastating whirl formed in 1921 when a magnitude 7.9 earthquake 
hit the Tokyo, Japan area causing a mass urban fire. This fire spawned an extremely large fire whirl that killed an estimated 38,000 people in less than 15 minutes [7]. The victims had gathered in an area of sparse fuel $0.16 \mathrm{~km}^{2}$ in size, and the whirl moved over the area. Last, the World War II city bombings of Hamburg, Dresden, and Hiroshima were reported to have caused very large and destructive fire whirls. The Hamburg whirl was estimated at 2.4 to 3 kilometers in diameter and 5 kilometers tall [8].

Large and intense fire whirls also occur on wildland fires. Graham [9-11] describes several large whirls that were able to lift large logs and other debris and break off large standing trees. He indicates that many form on lee slope locations. Pirsko et al. [12] report on a very intense fire whirl that moved out of the fire area in the downwind direction and destroyed 2 homes, a barn, and 3 automobiles, toppled almost 100 avocado trees, and injured 4 people. They also believe that the terrain and lee slope fire location contributed to the formation of the whirl. Additionally they cite moderate winds, an unstable atmosphere, and a large heat source as contributors. King [13] analyzed video of a fire whirl and found that maximum vertical velocities in the whirl core were up to $91 \mathrm{~m} \mathrm{~s}^{-1}$. Large fire whirls have also been documented on flat ground. Haines and Updike [14] describe several medium to large size fire whirls that occurred during prescribed fires on flat ground. They cite a superadiabatic lapse rate in the lower atmosphere as an important factor. Umscheid et al. [15] also report on a large fire whirl that occurred on flat ground and give convincing arguments that a major contributor to the whirl was vorticity associated with passage of a cold front. Billing and Rawson [16] also report on a large whirl that may have been influenced by a cold front passage. McRae and Flannigan [17] describe many large whirls that occurred on prescribed fires. One of the largest and most intense whirls was 400 meters in diameter and ripped standing trees out of the ground and lifted them upwards. This whirl occurred on a cloudy day with a temperature lapse rate of $-6^{\circ} \mathrm{C} / 1000 \mathrm{~m}$ in the first 1000 meters above the ground. They conclude that the influence of the environmental lapse rate on fire whirl formation is unclear and that whirls can form under lapse rates other than dry or super adiabatic.

Fire whirls have severely injured firefighters in the past. Emori and Saito [18] describe a wildland fire in Japan that may have spawned a fire whirl that injured firefighters. The 2001 Fish Fire in Nevada generated a fire whirl that caused firefighters to deploy their fire shelters [19]. Another whirl in 2006 in Nevada injured 6 firefighters [20]. Finally, a very large whirl formed on the 2008 Indians Fire in California that injured 4 firefighters [3].

3.1. Fire Whirl Physics. Over the past few decades, a significant body of information has accumulated on fire whirl structure and influencing factors. The different techniques used to investigate fire whirls include field [10-15, 17, 21, 22] and laboratory $[1,7,18,23-37]$ scale experiments, and analytical $[1,23-26,30,38,39]$, physical $[1,7,18,26,27,29$, $33-36,40]$, and numerical $[15,23,24,41-46]$ modeling. This work has revealed some of the main features of fire whirls. For example, it is commonly accepted that the formation of fire whirls requires a source of ambient vorticity and a concentrating mechanism [1, 2, 23, 41, 42]. Ambient vorticity in the atmosphere can be generated by the ground boundary layer of wind, by wind shear from nonuniform horizontal densities, and from the earth's rotation. The concentrating mechanisms in fires are produced by the buoyant flow. They reorient horizontal vorticity into the vertical direction and provide vortex stretching.

3.1.1. Whirl Structure. One of the first laboratory studies of fire whirls was that of Emmons and Ying [1]. They were able to generate a fire whirl with a combusting core by placing a liquid-fueled (acetone) pool fire in a cylindrical rotating screen. The rotation speed of the screen was varied, and temperature, velocity, and burning rate were measured. Several important aspects of fire whirls were identified in this study. They found that a fire whirl develops an ascending and rotating core of fuel rich gas. The core's radial distribution of tangential velocity may be in more or less "solid body" rotation (also called a forced vortex), but Emmons and Ying were not able to take measurements to prove this. In a forced vortex, vorticity and angular frequency are constant and non-zero. Tangential velocity and circulation increase with radius. Outside of this core, Emmons and Ying describe a fuel lean area with tangential velocity that can be well described by a free or potential vortex plus small radial and vertical velocity components. Vorticity in a free vortex is zero, while angular velocity and frequency tend toward zero with distance from the axis. Snegirev et al. [24] state that the free and forced vortex system can be approximated with a Rankine vortex as shown in Figure 2, which is an analytic equation sometimes used to approximate the velocity structure in tornadoes and hurricanes. Their numerical model which used a k-epsilon turbulence closure modified for swirling flows did indeed show that the radial profile of tangential velocity closely resembled the Rankine vortex. Chuah and Kushida [25] and Chuah et al. [26] use Burger's vortex as an estimate for the core flow in their analytical model. Burger's vortex is an exact analytical solution to the Navier-Stokes equations that is sometimes used to describe vortex tubes. They also state that the radial inflow velocity needed to maintain the vortex is a function of the core radius with a smaller core radius requiring more radial inflow to maintain the vortex.

Akhmetov et al. [27] used a PIV method on a laboratorygenerated fire whirl to provide currently the best measurements of the velocity structure in a fire whirl. They confirmed that a fire whirl generates a core region that rotates in approximately solid body rotation. The maximum vertical velocity in the core region was of the same order of magnitude as the maximum rotational component. Outside of the core, the rotational velocity component decreases with distance from the axis, and vertical velocities are much less. They also concluded that the basic features of fire whirl flows are the same as in other vertical tornado-like vortices such as dust devils and tornados. 


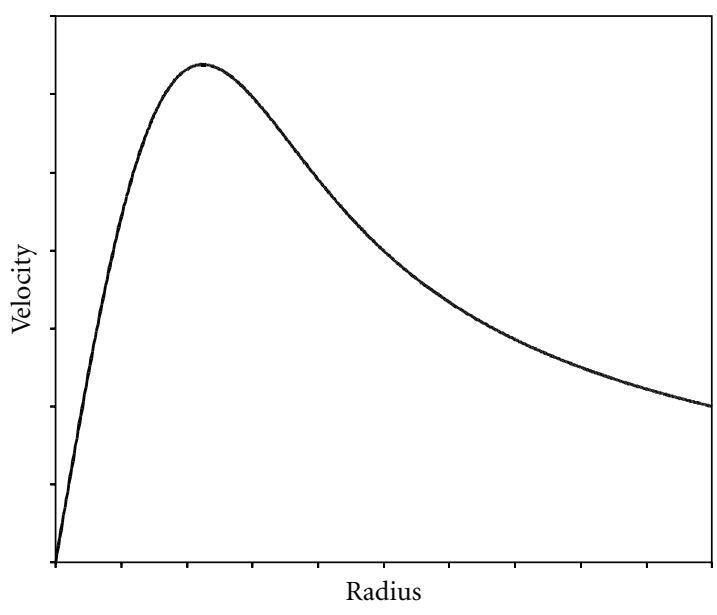

FIgURE 2: Tangential velocity structure as a function of radius for a Rankine vortex.

3.1.2. Turbulent Mixing. Emmons and Ying [1] also found that the rotational motion in and at the boundary of a fire whirl core causes an order of magnitude reduction in turbulent mixing motions. This is what gives a fire whirl its tall, slender appearance. They indicate that this turbulent mixing reduction is a very significant aspect of swirling flows and one of the main reasons that fire whirls are able to achieve such strong intensities. Snegirev et al. [24] expand on the turbulent suppression idea explaining that, in the core, radial displacement of a fluid particle towards the axis is resisted by centrifugal acceleration and displacement away from the axis is resisted by the radial pressure gradient. Because of the solid body rotation in the core, this radial pressure gradient increases with radius. The turbulence suppression in the core is analogous to that in a stable atmospheric boundary layer, but with different resisting forces. In the outer, free vortex area, fluctuations in the radial direction are destabilized, analogous to an unstable atmospheric boundary layer. Others [28, 29] have examined turbulence in laboratory fire whirls and jets in more detail and also showed a large reduction in turbulence in the whirl core. Some have proposed the use of a Richardson number for examining the stability of fire whirls [24, 29].

Emmons and Ying [1] indicate that the stable core environment could lead to the existence of "surface waves" on the surface of the core, similar to water flowing in a river or stable atmospheric flow over a hill. In the case of the upward flow being faster than the surface wave speed "shooting flow", a hydraulic jump type situation is possible [42]. This jump from the so-called "shooting flow" to "tranquil flow" (flow speed slower than wave speed) would be accompanied by high turbulence, which could contribute to vortex breakdown, although this has never been confirmed. Emmons and Ying [1] also mention that a hydraulic jump may be necessary if the whirl is to satisfy its ground-level and "high-" altitude boundary conditions for momentum and mass flow. This might be similar to water flowing down a dam spillway, where the initial velocity is high (supercritical flow) but it flows into an environment of much slower flow (subcritical flow) at the end of the spillway. The flow must form a hydraulic jump to satisfy these boundary conditions in a stable flow environment. Komurasaki et al. [43] used numerical simulation to investigate vortex breakdown in a thermal whirl and found that just as vortex breakdown begins, strong vorticity appears near the ground. This strong vorticity was attributed to strong jets of downward moving air that impinge on the ground during the breakdown of the simulated whirl, which, if true, could have safety implications for nearby firefighters.

It should be noted that several authors have found that, at very low rotation, a plume actually expands more than the nonrotating plume and reduces the flame height. As rotation is increased, turbulence is suppressed as discussed above and the plume expands less than the non-rotating plume giving a taller, more slender plume. Emmons and Ying [1] show this in Figure 7, but cannot explain this behavior. Battaglia et al. [44] also showed this behavior in their numerical model. Zhou and $\mathrm{Wu}$ [23] explain this by stating that it is due to the inflow boundary layer wind reducing the initial vertical velocity of gas and enhancing entrainment.

The large reduction of turbulent mixing in the core of a whirl is one of the principle causes of the amazing velocities fire whirls can achieve. The low turbulence reduces transfer of momentum, mass (density), fuel, and oxygen to and from the core. In whirls with a combusting core, this causes a large increase in flame lengths since the flames are turbulent diffusion flames and mixing with oxygen outside the core is limited. Emmons and Ying [1] report flame length increases of up to 7 times the nonwhirl lengths, although the increased flame lengths include the combined effect of turbulent reduction in the whirl core and increased evaporation rates of the acetone pool. Chigier et al. [28] used a metered methane burner to keep gas flow rates constant and showed that flame lengths doubled in their laboratory whirl produced using a rotating mesh cylinder. Since the fuel flow was held constant, this increase in flame lengths was due solely to the reduction in mixing. Even in whirls with noncombusting cores, this low turbulent mixing produces a tall column of lower density gas than the surrounding atmosphere. Consequently, pressure at the ground level in the core may be very low [1] due to this hydrostatic effect. This combines with the cyclostrophic flow effect discussed in the next section to produce extremely low pressures near the ground.

3.1.3. Cyclostrophic Flow. Contributing to a low pressure in the core is the roughly cyclostrophic flow (pressure gradient force balances the centrifugal force) [38]. As the whirl spins faster, lower pressures occur in the core to balance the increased centrifugal force. Near the ground, this cyclostrophic balance is disrupted by drag forces and the large radial pressure gradient produces flow toward the axis of rotation. Consequently, flow near the ground converges toward the center of the whirl and then is forced vertically. This draws air, rich in shear-produced horizontal vorticity, into the bottom of the whirl [42]. Also, additional buoyant gases and fuel may be drawn into the core, aiding vortex 
stretching [1]. Muraszew et al. [30] state that this effect due to the ground surface is a requirement for the formation of a fire whirl.

3.1.4. Vortex Stretching. The primary vorticity concentrating mechanism in fire whirls appears to be vortex stretching due to vertically accelerating flow in the whirl core [24]. This corresponds to the second term on the right-hand side of (3). The vertical acceleration is due to buoyant forces from hot gases in the core of the fire whirl. This acceleration causes a reduction in the diameter of a horizontal area enclosed by a chain of fluid particles (horizontal convergence), thereby increasing nonzero vorticity at any location on the horizontal area [38]. This is analogous to a reduction in the moment of inertia of a rotating solid, causing increased rotation rate to conserve angular momentum. Snegirev et al. [24] indicate that the whirl core radius is not dependent on the initial or imposed circulation but that it is probably dependent on vortex stretching due to vertical acceleration.

This same mechanism may also contribute to reduction in whirl vorticity [24] high up in the vortex where the vertical velocity decreases with height. This could occur when the core's buoyancy is reduced from ambient air entrainment and/or encountering a stable atmospheric lapse rate aloft. The vertical deceleration would reduce the vorticity.

3.1.5. Increased Combustion Rates. A number of researchers have noted significant increases in burning rates of laboratory fire whirls $[1,26,31,32]$. In all of these studies, the burning rate is defined as the mass loss rate of the fuel source (solid or liquid). Byram and Martin [31] found a threefold increase in alcohol burning rate when a whirl formed. Emmons and Ying [1] found that the burning rate of their acetone pool fires was a function of the externally imposed circulation, with increases of up to 7 times the nonwhirl conditions. Martin et al. [32] measured 1.4 to 4.2 times faster burning rates in fires fueled by cross-piled wood sticks of varying sizes.

The increased burning rate is likely due to increased heat transfer and mixing near the solid or liquid fuel. The question of which mechanism of heat transfer (convection or radiation) is causing the increased burning rates has been examined by several researchers $[24,26,28]$. Most have speculated that increased convective heat transfer due to high levels of turbulence near the ground surface and fuel causes the increased burning rates [24, 28]. Snegirev et al. [24] used a CFD model that included a Monte Carlo radiation solver to show that radiation actually decreased when a whirl formed in their study. This was attributed to changes in flame shape and suggests that radiative heat transfer is not the cause of increased burning rates in fire whirls. These authors propose that the flow rotation intensifies the entrainment of air into the fuel-rich region near the ground and fuel surface, which causes increased mixing in this area resulting in higher gas temperatures and reaction rates. Chigier et al. [28] used an isothermal laboratory experiment to show that increased mixing does occur. Their experiment used a suction tube to produce the needed vortex stretching. The isothermal nature of the experiment allowed easy measurement of velocity, including turbulence. They found that turbulence intensities over the first four diameters vertically were much higher than the nonrotating case. Above this height, turbulence intensities reduced to less than the nonrotating case as expected. Chuah et al. [26] used a scaling analysis and measurements in small experimental fire whirls over pool fires to develop an analytical model of fire whirls, including a heat-feedback mechanism to the pool fire. They found that the average rate of heat transfer from the flame to the fuel surface was a function of the vortex core radius. A smaller radius provided more heat to the fuel surface.

3.1.6. Scaling Fire Whirls. Much of what is known about fire whirls comes from small-scale laboratory experiments. Full scale experiments are usually not practical because of safety concerns, economic aspects, and difficulties of controlling boundary conditions [18]. Because of this, scaling laws are very important to consider when attempting to apply information gained from small-scale experiments to fullscale fire whirls. Several authors have examined scaling related to fire whirls.

One of the first investigations of scaling laws related to fire whirls was Emmons and Ying [1]. They suggest that Froude and Rossby numbers were important parameters for understanding their laboratory whirls. Another investigation was that of Emori and Saito [18]. They used a scale model in a wind tunnel to recreate a firefighter entrapment that occurred. The scaling analysis concentrated on fluid flow and buoyancy from the fire, which was simulated in the scale model using electrically heated wires. A modified Froude number was considered important to proper scaling. In the experiment, they found that a fire whirl occurred on the lee side of a mountain at the location where the firefighters were injured. They also found that the whirl only formed when the ambient cross-flow wind was within a certain speed range. Wind above or below this range did not produce a fire whirl.

Soma and Saito [7, 33] classified whirls into three different types according to causal factors and behavior and investigated each type using scaling analysis and experiments. Their scaling analysis determined that scaled experiments should be performed with wind velocities and heat generation rates proportional to the square root of the fire widths or one-fourth power of the fire area. They were able to produce fire whirls in their experiments that qualitatively matched the full-scale events. Length scale ratios between the experiments and full-scale whirls were $1 / 235,1 / 2500$, and $1 / 4837$. They also found that there was a range of cross-flow wind speeds where whirls would form but above or below this speed whirls did not form.

Grishin et al. [34] examine fire whirls using laboratorygenerated whirls and found that Grashof and Froude numbers could be used for scaling. They conclude that fire whirl characteristics are determined by the heat-flux density, lift force, and angular momentum of the external vortex flow. Grishin et al. [35] use a Rossby number derived in a semiempirical way to determine the critical values 
under which a fire whirl would form in their laboratory experiments. They state that the rotation velocity of a fire whirl decreases as its radius increases and increases as its height increases. Akhmetov et al. [27] also use a Froude number for scaling and find that rotational velocity increases as whirl height increases. They mention that other similarity criteria based on Grashof number or Reynolds number will vary by many orders of magnitude for vortices of different scales.

To the authors' knowledge, the only discussion of the horizontal movement of fire whirls is given by Grishin [39] despite its importance to firefighter safety. The paper uses a theoretical basis to analyse how fire whirls move due to interaction with other fire whirls. In particular, two counterrotating fire whirls with equal intensity in close proximity are examined and found to move in the same direction with the same velocity. This could be important in the case when counter-rotating vortices appear on the lee side of a fire plume $[21,45]$, which may be fairly common in wildland fires in a cross-flow wind.

Kuwana et al. [36, 40] examined several experimental and full scale whirls under cross flow conditions and concluded that a critical cross flow wind velocity exists where fire whirls are most likely to occur. This critical velocity was found to be proportional to the vertical buoyant velocity, which depends on the burning rate and length scale of the burning area.

3.1.7. Vorticity Sources. In the wildland fire context, it appears that there are many possible sources of ambient vorticity that could contribute to fire whirls. Morton [47] discusses some of these sources. One important source may be the vertical shear layer that develops when ambient wind flows over the ground surface, producing horizontally oriented vorticity. This type of vorticity generation corresponds to the fourth term on the right-hand side of (3). As shown in Figure 3, this horizontal vorticity can then be reoriented, or tilted, by the fire's buoyant flow into the vertical $[21,38$, 45] and may be a major contributor to many fire whirls. Similarly, it is likely that the drafting to a buoyant plume develops a shear layer near the ground that also generates horizontally oriented vorticity that can also be tilted to the vertical. This source of vorticity could be present even in zero ambient wind situations. Complex terrain can also generate vorticity through channeling and shear of ambient and fire-induced winds [12]. Turbulent wake regions behind terrain features such as hills and mountains are thought to produce favorable vorticity for fire whirls [2, 11, 48, 49]. Another source of ambient vorticity for some whirls may be vorticity present along frontal boundaries $[15,16]$. This may be similar to the meteorological setting for many nonmesocyclone tornadoes [15].

Another possible source of vorticity in fire whirls is the baroclinic term in (3). At this time, it is unclear how important this source of vorticity is to fire whirls. McDonough and Loh [46] provide an initial examination using numerical modeling. They mainly examine grid resolution requirements and are not able to make any strong conclusions about the significance of baroclinically generated vorticity, other than that it warrants further study.
3.2. Fire Whirls in the Real World: Common Features. There appear to be many factors that influence the development of fire whirls on wildland fires. These factors interact in complex ways, and it is doubtful that firefighters will ever have very accurate predictive tools to foresee whirl formation, especially in a timely manner to make real-time decisions. The hope at this point is to identify situations that are more likely to form whirls. The following are some likely scenarios where fire whirls have been known to form. It is probable that some of these types of fire whirl scenarios could be combined to possibly make whirl formation more likely or more intense.

3.2.1. Whirl Shedding on the Lee Side of a Plume. This type of whirl forms when a plume is subjected to a cross-flow wind. The whirl forms on the lee wind side of the plume. It separates from the plume and advects in the downwind direction. Sometimes multiple whirls of opposite rotating direction shed periodically, similar in appearance to Von Karman vortex shedding behind an obstruction in a flow. Often, as the whirl moves away from the fire, it contains no flaming combustion. Wind in these whirls can be strong enough to cause damage to trees, structures, vehicles, and so forth. and the whirl may stay intact for several minutes and travel for distances of possibly 1 mile. Its ability to stay intact even though most of its vortex stretching mechanism (buoyancy) is lost is probably due to the strong reduction in turbulent diffusion of the core. Examples of this type of whirl have been reported by many authors $[6,7,12,21,22,33,50]$, and video and images of others are on file at the US Forest Service's Missoula Fire Sciences Laboratory.

It is probable that a critical cross-flow wind velocity is very important to this type of fire whirl, as discussed in Section 3.1.6. Cunningham et al. [45] were able to simulate this type of whirl and hypothesized that the main source of vorticity comes from the tilting of horizontally oriented, shear-generated vorticity in the ambient cross-flow. The significance of other sources of vorticity is currently unknown. Others [51-53] have shown that the same shedding whirls are present in an isothermal vertical jet in cross flow, although in these experiments the whirl formation may also be influenced by the jet shear layer.

3.2.2. L-Shaped Heat Source in Cross-Flow. Soma and Saito $[7,33]$ first investigated this type of fire whirl as an explanation for a historic and catastrophic fire whirl that occurred in 1923 in Tokyo. Unlike the shedding whirl, this whirl seems to be mostly stationary. It occurs when a roughly L-shaped heat source is subjected to a cross-flow wind as shown in Figure 4. The whirl forms in the inside bend of the L-shaped heat source. As in the shedding whirl, a critical cross-flow wind speed is thought to be important $[7,33]$. If the wind is above or below this speed, whirls are less likely to form. This type of whirl is probably very much related to the shedding whirl type, including the important vorticity source from the ambient shear flow.

3.2.3. Vorticity Associated with Cold Fronts. This type of whirl forms when ambient vertical vorticity from cold fronts 


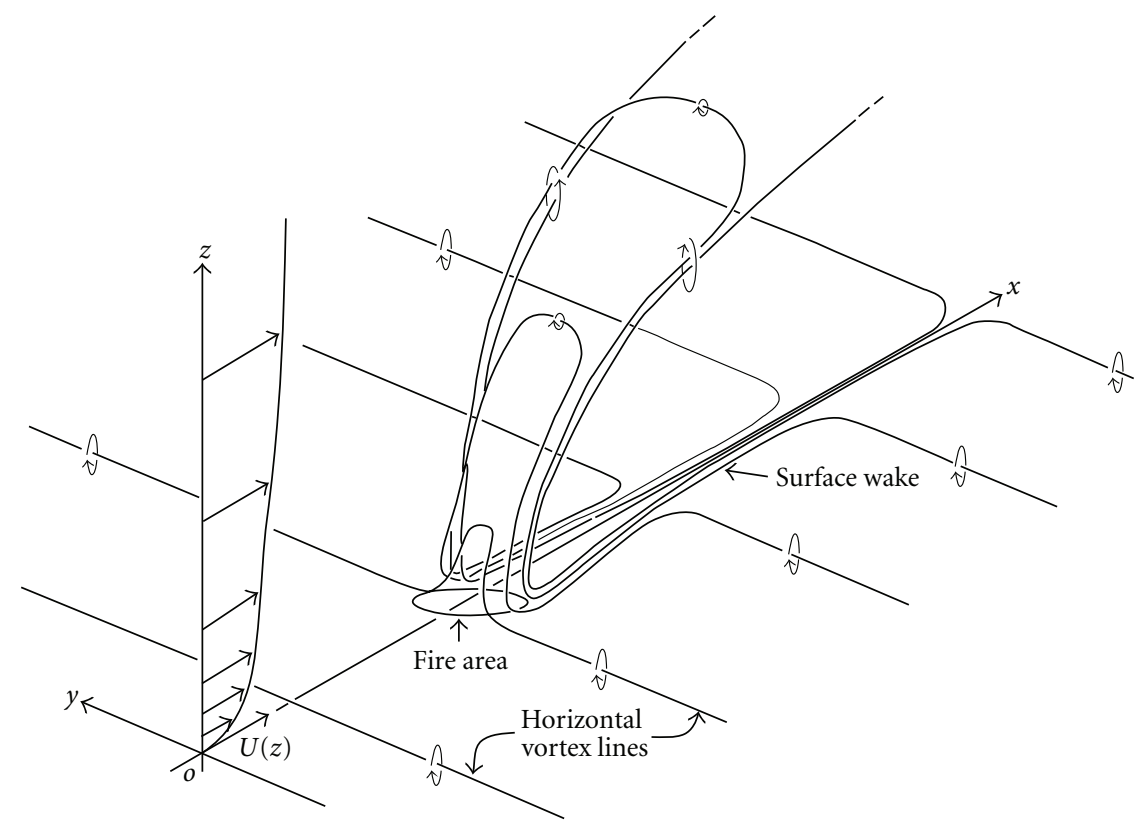

FIGURE 3: A schematic showing how shear-generated horizontal vorticity present in the atmosphere near the ground can be reoriented to the vertical by a fire (from Church et al. [21]).

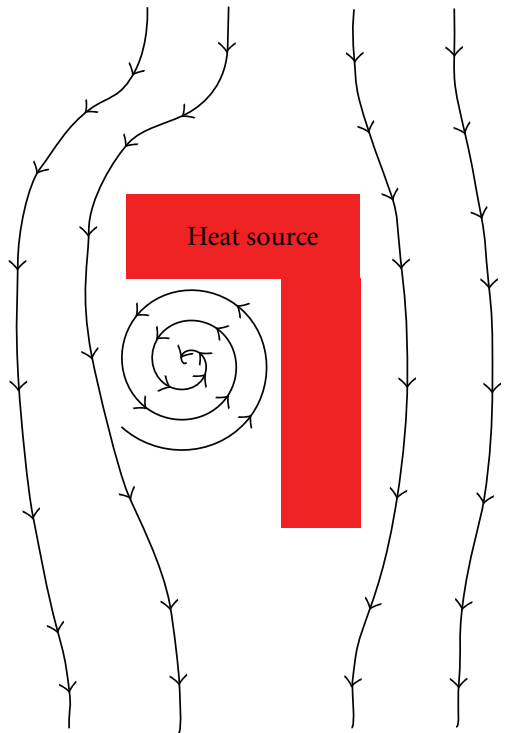

FIGURE 4: Schematic of fire whirl formation for an L-shaped heat source in a cross-flow wind. View is from above.

interacts with a fire plume. Billing and Rawson [16] and Umscheid et al. [15] discuss cases where this type of whirl formed over flat terrain. The key feature of these two examples is that they occurred almost exactly when a cold front passed over the fire area. Umscheid et al. [15] discuss the associated ambient vertical vorticity present along a cold front boundary and identify some similarities between this type of fire whirl and the formation mechanisms of nonmesocyclone tornadoes. At this time, it is not clear why fire whirls form under some cold front passage conditions, but not others. Perhaps nonmesocyclone tornado genesis research can help identify why these whirls form.

3.2.4. Multiple Interacting Plumes. This type of fire whirl occurs from the interaction of multiple plumes with no ambient cross flow wind. Entrainment into each plume is affected by the nearby plumes, and under the correct configuration and buoyant plume strengths, a whirl can form. Figure 5 shows a schematic of how five fires could be oriented to cause a fire whirl. Lee and Otto [37] observed whirl formation due to plume interaction in their experiment using two asymmetric shaped burning wood piles. Zhou and $\mathrm{Wu}$ [23] examined the multiple interacting plume whirl in more detail using experimental fires, numerical simulation, and some scaling analysis. They discussed configurations under which whirls would and would not form. They also showed that whirls can form under randomly oriented plume locations (Figure 6). This has implications to wildland fire under mass spotting type conditions. Occurrence of fire whirls under such conditions might be very likely, so long as the multiple plumes are drafting a significant amount of air and are properly spaced and organized.

3.2.5. Lee Side of a Hill/Mountain. These fire whirls occur when a fire plume exists on the lee side of a terrain obstruction such as a hill or mountain. The plume uses vorticity existing in the wake region of the obstruction to form the whirl. Countryman [49] states that this is the most favorable situation for generation of fire whirls. During investigations of full-scale mass fires, Countryman [48] intentionally burned a fire on a lee slope under moderate wind to investigate this type of whirl. Several whirls formed during the burn, with the largest occurring near the end. 


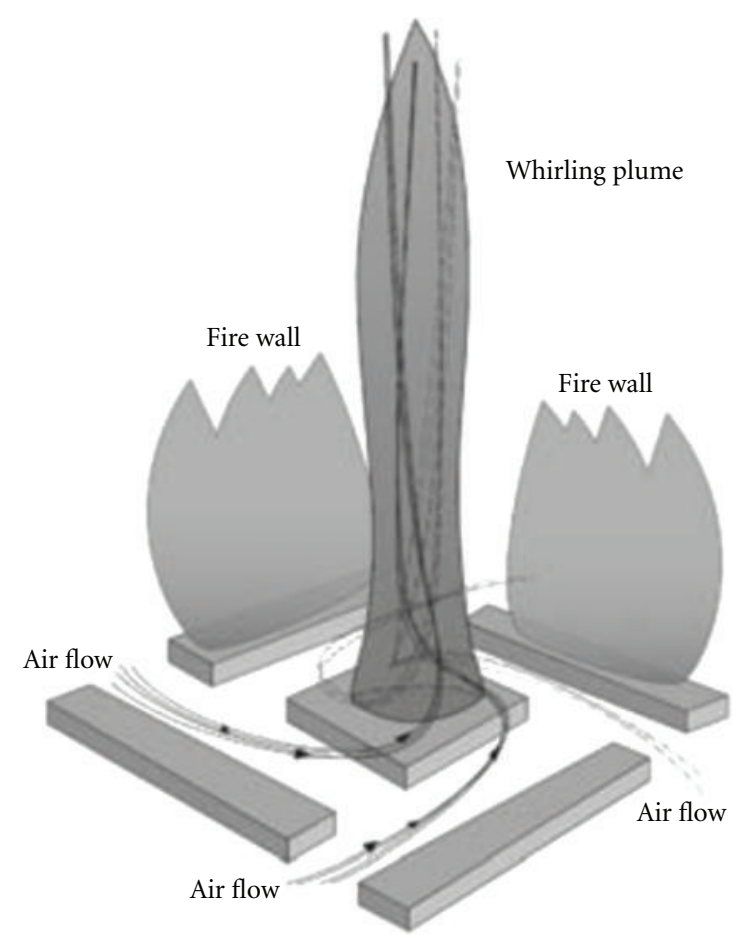

FIGURE 5: Schematic showing a heat source configuration that can cause a multiple interacting plume-type fire whirl (from Zhou and $\mathrm{Wu}[23])$.

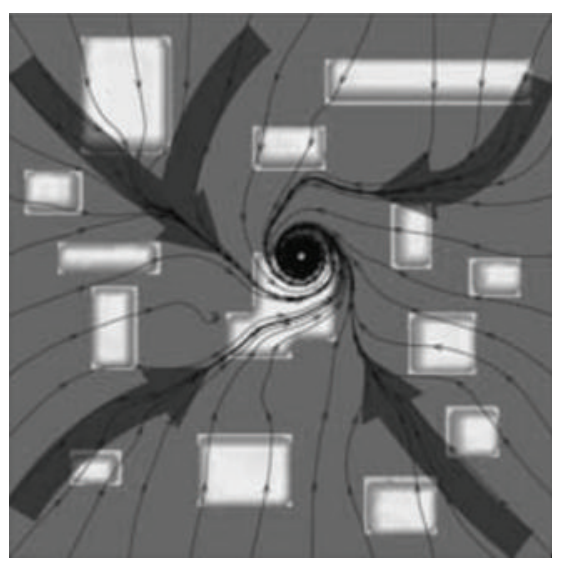

FIGURE 6: Image of a computer simulation showing how randomly oriented heat sources could cause a fire whirl through plume interactions. View is from above and heat sources are in lighter color (from Zhou and $\mathrm{Wu}$ [23]).

Pirsko et al. [12] describe a whirl that formed on the lee side of a terrain obstruction and then shed from the plume in the downwind direction. The whirl caused significant wind damage to several houses, trees, and vehicles. Wind speed at the time was $9.4 \mathrm{~m} \mathrm{~s}^{-1}$ with gusts to $13 \mathrm{~m} \mathrm{~s}^{-1}$.

\section{Horizontal Vortices}

Horizontal vortices are quite common in the atmosphere and have been extensively studied see Brown [54] and

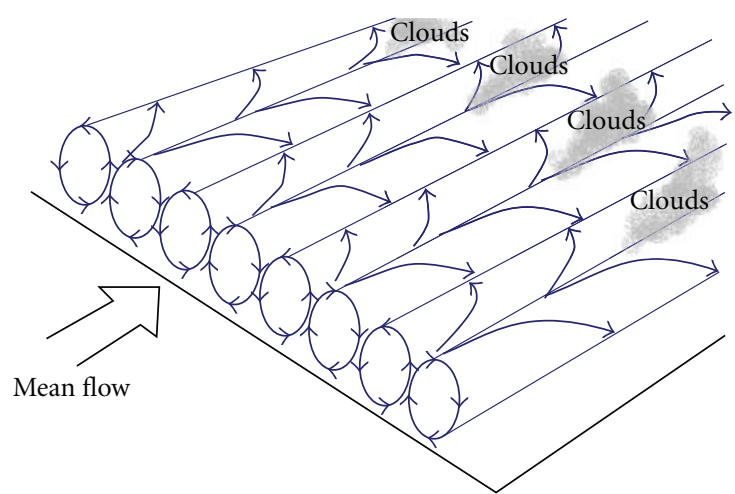

FIGURE 7: Illustration of the role of horizontal vortices in the development of cloud streets (based on Etling and Brown [55]).

Etling and Brown [55] for reviews. In the absence of wind, when the ground is heated, the warm air near the ground will eventually begin to rise in circulation cells, a process known as Rayleigh-Bernard convection [56]. In the presence of vertical wind shear, these cells begin to transition from disorganized and transient to an organized state of a hexagonal lattice of convective cells. Fair weather cumulus clouds often mark the tops of updrafts of these cells. As the wind shear increases, the convective cells further organize into horizontal convective rolls that are perpendicular to the mean wind; further increases in the vertical wind shear change the balance between buoyancy-driven vorticity and shear driven vorticity and lead to the convective rolls being oriented parallel to the mean wind [57]. These longitudinal convective rolls are easily seen in satellite images due to parallel bands of cumulus clouds known as cloud streets. Figure 7 provides an illustration of the structure of these cloud streets. While such horizontal convective rolls are a common feature of the atmosphere in the planetary boundary layer, the presence of a fire adds a complicating factor in the form of a horizontal temperature gradient that can locally alter the convective organization of the boundary layer.

Horizontal vortices associated with wildland fires have received less attention than their vertical counterparts, fire whirls. Haines and Smith [58], hereafter HS87, provide descriptions of three distinct types of horizontal vortices observed on wildland fires: the transverse vortex which is perpendicular to the flow direction, a single longitudinal (flow parallel) vortex, and a counter-rotating longitudinal vortex pair.

4.1. Transverse Vortices. Transverse vortices are described in HS87 as a series of vortices "climbing" the upstream side of the convective column under conditions of low ambient wind speeds and intense burning. The mechanism HS87 proposed for the development of such vortices involves the development of buoyancy-forced ring vortices rising through the smoke column. HS87 further hypothesize that only the upwind portion of the ring is clearly visible as turbulent mixing is thought to render the downwind section of the 
ring less distinct. While transverse vortices on wildland fires have received little attention, extensive literature is available on ring vortices associated with pool fires.

The buoyantly forced ring vortex is a common feature of fluid flows associated with heat sources ranging in scales from candles to pool fires up to large mass fires; however, they are most clearly visible under conditions of weak mean horizontal flow. For these ring vortices, the vorticity is generated through the baroclinic term from (3). Since the thickness of the density layer controls the magnitude of the baroclinically forced vorticity, the strongest vortices have scales similar to that of the flame surface [59]. As buoyant forces cause these vortices to rise, a process often referred to as "amalgamation" takes place as the rising vortices merge and grow and manifest themselves in the oscillatory necking and bulging of the fire that results from the Rayleigh-Taylor instability. The same basic process can be observed at the scale of the smoke plume, leading to the development of the transverse vortices described by HS87. The oscillatory nature of the development of these vortices has been extensively studied for pool fires [60]; however, little has been done at the scale of wildland fire events.

While descriptions of vortex rings are quite common in the literature, little is mentioned about transverse vortices outside of HS87. These vortices manifest themselves on the upwind side of the plume and add a boiling appearance to the plume. While the vortices themselves are not a source of erratic fire behavior, their presence is an indicator of a potential increase in the rate of combustion and an associated change in fire behavior.

\subsection{Longitudinal Vortices}

4.2.1. Single Longitudinal Vortex. Longitudinal vortices differ from their transverse counterparts in that their axis of rotation is oriented parallel to the mean flow. The first class of longitudinal vortices from HS87 is the single longitudinal vortex, of which only one case is presented, the Dudley Lake Fire as described by Schaefer [61]. The vortex was oriented in the direction of the mean flow, which was quite strong that day as surface winds were between 16 and $22 \mathrm{~m} \mathrm{~s}^{-1}$. The diameter of the vortex was estimated at 1,800 meters. Smoke entrained within the vortex delineated the corkscrew-like nature of the vortex and allowed the vortex to be observable $500 \mathrm{~km}$ downwind. The scale of this vortex is similar to those of the convective boundary layer rolls responsible for cloud streets and shows strong similarities to roll vortices associated with other crown fires [62] with the main exception being that this was only a single vortex.

A possible answer to the question of why only a single vortex was observed may be given through the numerical modeling work of Heilman and Fast [63]. In this study a computer model of the atmospheric boundary layer was initialized with multiple heat sources some distance apart to examine how circulations induced by each heat source interacted and how the collection of these flows responded to the introduction of a transverse wind component (wind blowing perpendicular to the axis of the roll vortices).
The introduction of the transverse wind component tended to destabilize the longitudinal vortices and in some cases eliminated the upwind vortex entirely. Haines and Smith [64] similarly found in their wind tunnel studies that a slight transverse component to the flow destabilized the vortex pair, causing the collapse of the downwind (relative to the transverse wind component) vortex, which on a wildland fire would cause the vortex to fall outward across the flank of the fire, providing an additional mechanism for lateral fire spread and a threat to firefighter safety. On the Dudley Lake fire, Schaefer [61] observed, at regular intervals, the outward/downward moving segments of the vortex would mark lateral surges in the fire growth, indicating the possible presence of some slight shifts in the wind that may have inhibited the presence of the other vortex.

This vortex type differs from the other two types described in HS87 in that the fire is not necessarily an integral forcing term in the development of the vortex. Conditions in the atmosphere may already favor the development of the convective rolls and the fire may simply act to enhance the vortex through additional thermal instability. While the transverse vortices are most pronounced at low wind speeds, the Dudley Lake vortex was accompanied by surface winds of 16 to $22 \mathrm{~m} \mathrm{~s}^{-1}$ (the mean wind speed for the 12 crown fire cases in Haines 1982 was $5.5 \mathrm{~m} \mathrm{~s}^{-1}$ ).

4.2.2. Counter-Rotating, Longitudinal Vortex Pair. Of the three types of horizontal vortices described by HS87, the counter-rotating, longitudinal vortex pair is the best documented, although early work $[65,66]$ focused on vortex pairs associated with smokestack emissions rather than wildland fires. The key feature of this vortex type is obviously the paired nature of the vortices rotating in opposite directions. These vortices often occur along the flanks of the fire and can also be observed in the main plume at the head of the fire; this is often referred to as a bifurcating smoke column. Figure 8 shows a numerical simulation of a bifurcated smoke plume as viewed from behind the fire. Cunningham et al. [45] showed that the degree to which the smoke plume splits is related to the depth of the surface shear layer.

The New Miner fire in central Wisconsin in 1976 is one example of a bifurcated smoke column provided by HS87. This fire burned under very low relative humidity conditions for the region (minimum of 23\%) with light winds averaging around $2 \mathrm{~m} \mathrm{~s}^{-1}$. The bifurcated column consisted of a pair of vortices approximately 30 meters in diameter which rotated fairly slowly compared to other atmospheric whirls like tornadoes. These columns would intermittently collapse and spill over the fire's flanks, bringing hot gases and embers into contact with unburned fuels and providing for rapid lateral spread. Obviously such behavior is a threat to fire crews that often focus their suppression efforts along the flanks of the fire. A key difference between these vortex pairs and the single vortex is the scale; the bifurcated columns were approximately $30 \mathrm{~m}$ in diameter while the vortex on the Dudley Lake fire was over a kilometer.

As part of a 1979 study conducted at the Centre de Recherches Atmosphériques Henri Dessens in France, 


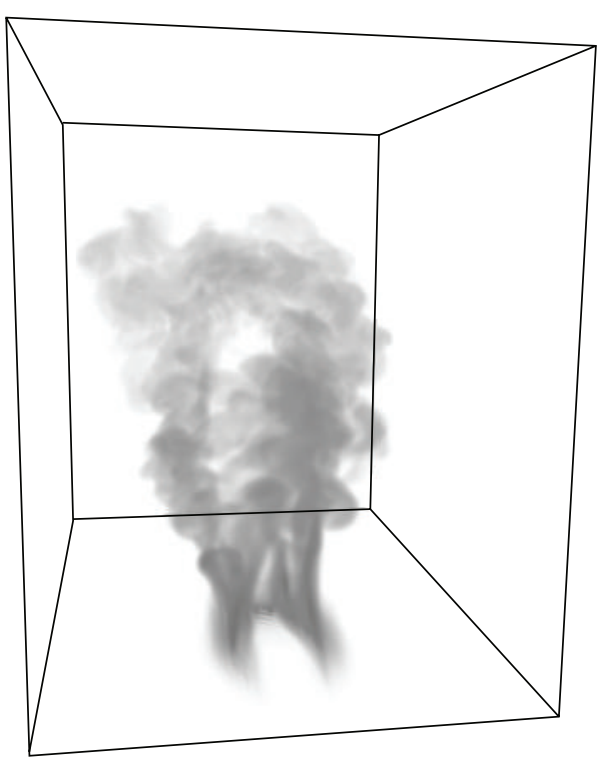

FIGURE 8: Bifurcated smoke plume from a computer simulation. View is from upwind of the fire (from Cunningham et al. [45]).

Church et al. [21] studied the vortices produced by the Météotron [67], an array of 105 oil burners with a total heat output of 1,000 MW. Three types of vortices were observed: (1) a columnar vortex that had the entire smoke column rotating, (2) small dust-devil like vortices just downwind of the burner array, and (3) large, counter-rotating vortex pair within the plume that started as vertical vortices at the burn site, but became horizontal and oriented parallel to the wind as the plume rose and moved downwind. The first two vortex types are vertical vortices as described in the section on fire whirls.

The last type resembles the bifurcating column described for the New Miner fire. At a height of 40-50 meters, the smoke column of the Météotron experiment bifurcated into a pair of counter-rotating vortices with initial diameters of 30-60 meters [21]. The dominant motion associated with these vortices was rotation about their axis with little noticeable motion along the axis, a stark contrast to the strong axial flow observed in many fire whirls.

The forcing of the counter-rotating vortex pair is complex and has parallels with the forcing of similar vortex pairs by nonbuoyant jets in a cross-flow (see Margason [68] for a review). The split plume develops through the interaction of the ambient vorticity in the flow due to vertical wind shear with the jet shear layer (or plume shear layer in the case of wildland fires). The presence of buoyancy adds additional complexity to the forcing of the split plume compared to the nonbuoyant jet. Church et al. [21] put forth a pair of physical processes capable of describing the development of the bifurcating smoke column. The first process focuses on the reorientation and stretching of the horizontal vorticity in the ambient flow. Initially, the ambient vorticity can be thought of as a collection of horizontal tubes oriented perpendicular to the wind with upward motion along the upwind side of the tube and downward motion along the downwind side. As these vortex tubes encounter the rising air at the fire, the portion of the tube over the fire is lifted which acts to tilt the vortex tube at the edge of the fire into a vertical orientation, producing a hairpin-like shape. As the lifted portion of the vortex tube continues to rise in the plume, it encounters stronger horizontal winds that transport this portion of the tube downwind faster than the surface parts, stretching the arms of the hairpin vortex. Eventually, the combined processes of the lifting and faster downwind transport lead to the majority of the hairpin vortex being oriented horizontal and parallel to the mean flow. This is illustrated in Figure 3.

The second process proposed by Church et al. [21] deals with the generation of vorticity through the combined effects of buoyancy and surface drag forces. This process is actually a variation on the buoyant rings discussed earlier. The variation is the impact of the cross-flow on the rising ring vortex. On the upwind edge of the ring, the cross-flow enhances entrainment of ambient air on that side of the plume which decreases the vertical velocity of that part of the plume. This causes the downwind section of the ring to rise faster than the upwind side, tilting some of the vorticity into a vertical orientation. The downwind section also encounters the stronger winds aloft before the upwind side which leads to a stretching/intensifying of the streamwise sections of the ring. Experiments by Tsang $[69,70]$ support the viability of this method in generating the counter-rotating vortex pair.

While both physical processes are plausible explanations for the development of the counter-rotating vortex pair, both are not equally supported by the observations. Many of the observed fire plumes exhibited significant near-surface vertical vorticity which is best supported by the first process which relies upon the reorientation of ambient vorticity [45]. Wind tunnel studies of the longitudinal vortex pair offer further support for the ambient vorticity process as Smith et al. [71] found the vorticity in the streamwise vortex pair to agree quite well with the vorticity of the ambient flow as it approached the heat source. This is not to suggest that the buoyancy generated from the fire has no impact, just that it is not the dominant forcing for the development of the vortex pair.

Numerical modeling studies of the longitudinal vortex pair have largely been two-dimensional $[63,72-74]$ or quasithree-dimensional (streamwise flow component assumed constant) where the governing equations are solved for a number of planes perpendicular to the streamwise flow [75-77]. Cunningham et al.'s work [45] was the first fully three dimensional simulation of fire plumes to focus on the development of vortical structures. Their simulations revealed the relationship between the depth of the shear layer, fire intensity, and the behavior of the vortex pair. The basics of this relationship centered around how long it took a buoyant air parcel to traverse the shear layer. Keeping the mean cross-flow constant, a deeper shear layer would lead to a wider split of the smoke column. If the fire intensity is increased, the air parcels travel through the shear layer faster which leads to a decrease in the width of the plume split. One interesting observation is that, for a given fire intensity, the 
TABLE 1: Common vorticity forms associated with wildland fires and their hazards.

Phenomenon
Fire whirl formation on the lee side of
plume
Fire whirl formation near an L-shaped
fire in a cross flow wind
Fire whirl formation near a cold front
Fire whirl formation due to multiple
interacting fire plumes
interacting fire plumes

Fire whirl formation on the lee side of a hill/mountain

Transverse vortex on upwind side of smoke column

Single longitudinal vortex

Counter-rotating longitudinal vortex pair
Causal factor(s)

Shear-generated vorticity near the ground is concentrated and reoriented to the vertical on the lee side of the plume.

Shear-generated vorticity near the ground is concentrated and reoriented to the vertical on the lee side of the $\mathrm{L}$, as shown in Figure 4.

Vorticity along the frontal boundary is concentrated in to a fire whirl.

The drafting and blocking effects of multiple interacting fire plumes concentrate vorticity that was likely shear generated near the ground.

Vorticity associated with the wake region of a terrain obstruction such as a hill or mountain is concentrated into a fire whirl.

Horizontal vorticity is produced through buoyancy.

Unstable atmosphere and strong winds generate horizontal vortices with axis parallel to the wind direction. Vortex formation is not tied to the fire.

Transverse ambient vorticity due to surface wind shear is altered by the fire as it is tilted into the vertical and reoriented to the longitudinal direction. Evident as a bifurcated smoke plume.
Potential danger

Increased energy release rate, spread rate, and spotting. The whirl could travel downwind from the fire and overtake firefighters.

Increased energy release rate, spread rate, and spotting. The whirl could suddenly form in the "interior" area of L.

Increased energy release rate, spread rate, and spotting.

Increased energy release rate, spread rate, and spotting. Whirl could build into a fire storm.

Increased energy release rate, spread rate, and spotting. The fire could quickly switch from a sheltered, backing fire with low fire behavior to more extreme fire behavior. The whirl could travel downwind from the fire and overtake firefighters.

Not a source of erratic fire behavior, but rather an indicator of a potential increase in the rate of combustion and an associated change in fire behavior.

Slight variations in wind direction can destabilized the vortex, causing the vortex to fall outward across the flank of the fire, providing a mechanism for lateral bursts in fire spread.

Can produce concentrated wind bursts at the head of the fire that lead to strong fingering of the fire front. The vortices are not always stable as variations in wind direction can cause one of the vortices to collapse and bring hot gases and fire brands into contact with the unburned fuel. plume rise is not affected by the width of the smoke column's bifurcation, although its horizontal spread and deviation from a Gaussian distribution is strongly impacted.

Another aspect of the counter-rotating vortex pair described by the numerical simulations of Cunningham et al. [45] is the potential for oscillations, with each branch periodically exhibiting dominance. These oscillations were linked with localized regions of vertical vorticity of alternating signs being shed from either side of the plume in a manner similar to wake vortices observed for fluid flowing around a cylinder. While these results were limited to a narrow range of flow parameters, these simulations indicate that the counter-rotating vortex pair is not necessarily stable. Wind tunnel studies using a heated wire to mimic the flank of a crown fire have shown that perturbations in the flow component perpendicular to the mean flow can cause the vortex pair to collapse [64]. These flow perturbations could be caused by upstream topographic features, possibly groups of trees, or even natural shifts in the ambient wind.

In the previous discussion, the wind profile reflected typical conditions where wind speed increased with height. Byram [78] noted that a number of major fire runs occurred when the wind speed decreased with height near the surface, a condition known as an adverse wind profile. Clark et al. [79] examined the potential impact of an adverse wind profile on fire spread through the use of a three-dimensional coupled fire-atmosphere model. In their simulations a counter-rotating vortex formed through the reorientation of the ambient boundary layer vorticity as described above; however, this time the rotation was in the opposite direction (see Figure 2 of Clark et al. [79]) which leads to narrow regions of hot, high-speed air shooting out of the fire front. This dynamic fingering occurred at scales of the order of tens of meters and has the potential to augment fire spread. 


\section{Summary}

Vorticity describes the degree of rotation in the atmosphere about some axis. Two factors that induce rotation in the atmosphere are wind shear and sharp horizontal gradients in temperature. Once one of these factors has generated vorticity, that vorticity can be transported by the mean wind to other locations, reoriented from one axis to another (a horizontal vortex can be tilted to become a vertical vortex), or enhanced due to flow convergence which stretches the vortex. It is rare for the atmosphere to be completely devoid of vorticity. If the wind is blowing at all, there is vorticity produced near the ground due to surface drag. Terrain features provide flow obstacles whose drag produces wind shear and thus generates vorticity. Different ground surfaces heat at different rates which also generates vorticity. Vortices are present across a broad spectrum of spatial scales, continuously transferring energy between scales, mostly from large scales to smaller scales. A fire not only interacts with and modifies this ambient vorticity, but also generates additional vorticity.

For convenience of our discussion of wildland fire vortices we split our discussion into vertical and horizontal vortices. Vertical vortices, often referred to as fire whirls, are often the most dramatic and often described type of vortex. Fire whirls, especially the larger ones, represent a considerable safety hazard to fire fighters as these vortices can result in sudden increases in fire intensity, spotting, erratic spread rate and direction, and damaging winds. Most often, the source of vorticity for a fire whirl is not the fire itself; rather, the vorticity is present in the ambient atmosphere. This ambient vorticity may be generated by wind shear, vortex shedding in the wake of a plume or topographic obstruction, or an approaching cold front. The fire plays a very important role in modifying the ambient vorticity field by tilting horizontal vortices toward the vertical and increasing the vorticity magnitude through the stretching term as surface flow converges at the fire to feed the strong updraft.

Similarly, two of the three horizontal vortex types described by HS87 rely upon ambient vorticity. The counterrotating vortex pair builds upon the tilting and stretching vortex modifications that enable a fire to transform horizontal vorticity generated by wind shear into a vertically oriented fire whirl. The key addition is stronger winds above the surface that sweep the upper part of the hairpin vortex described in Figure 3 downwind, bending the vortices back toward a horizontal orientation. For the single longitudinal vortex described for the Dudley Lake fire, the fire is interacting with vorticity on a much larger scale, a boundary layer roll whose depth can occupy the entire mixed layer. Again the fire's roll is one of modifying the vortex which can in turn modify the fire environment by changing wind flow patterns near the fire and creating a positive feedback loop leading to fire intensification.

Vortices are common features of the atmosphere occurring across a broad range of spatial scales. Our understanding of how wildland fires interact with this broad spectrum of atmospheric vortices is still very much in development.
Table 1 summarizes the various vortices described in the text along with their causes and potential threats. While the occurrence of these vortices is currently impossible to predict with precision, having a basic understanding of the importance of ambient atmospheric vorticity for vortex development provides some guidance on situations that require awareness. Examine surrounding topography relative to the expected wind direction, noting features that may block or channel the flow. Information on wind profiles when available can provide information on wind shear as can direction/speed of cloud movements and their organization (are the clouds forming in lines?). Observe the behavior of the fire and smoke plume. Vortices are almost always present along the flaming front at some scale. Watch for vortices that grow or persist. Watching the smoke plume for signs of rotation or splitting. While this information is not sufficient for predicting the occurrence of intense vortices on wildland fires, it can help identify potentially hazardous conditions.

\section{References}

[1] H. W. Emmons and S. J. Ying, "The fire whirl," in Proceedings of the 11th International Symposium on Combustion, pp. 475488, Combustion Institute, Pittsburgh, Pa, USA, 1967.

[2] D. W. Goens, "Fire Whirls," Missoula, MT: NOAA Technical Memorandum NWS WR-129, 1978.

[3] T. Moore, "Indians Fire accident prevention analysis," USFS Pacific Southwest Region, 2008.

[4] H. A. Musham, "The great Chicago fire," Papers in Illinois State History and Transaction, pp. 69-189, 1941.

[5] D. Gess and W. Lutz, Firestorm at Peshtigo: A Town, Its People and the Deadliest Fire in American History, Henry Holt Publishing, 2002.

[6] J. Hissong, "Whirlwinds at oil-tank fire, San Luis Obispo, California," Monthly Weather Review, vol. 54, pp. 161-163, 1926.

[7] S. Soma and K. Saito, "A study of fire whirl on mass fires using scaling models," in Proceedings of the First International Symposium on Scale Modeling, p. 353, The Japan Society of Mechanical Engineers, Tokyo, Japan, 1988.

[8] Ebert, "Hamburg's fire storm weather," NFPA Quarterly, vol. 56, pp. 253-260, 1963.

[9] H. E. Graham, "A firewhirl of tornadic violence," Fire Control Notes, vol. 13, pp. 22-24, 1952.

[10] H. E. Graham, "Fire whirlwinds," Bulletin American Meteorological Society, vol. 36, pp. 99-103, 1955.

[11] H. E. Graham, "Fire-whirlwind formation as favored by topography and upper winds," Fire Control Notes, vol. 18, pp. 20-24, 1957.

[12] A. R. Pirsko, L. M. Sergius, and C.W. Hickerson, Causes and Behavior of a Tornadic Fire-Whirlwind, USDA Forest Service, Pacific Southwest Forest \& Range Experiment Station, Berkeley, Calif, USA, 1965.

[13] A. R. King, "Characteristics of a fire-induced tornado," Australian Meteorological Magazine, pp. 1-9, 1964.

[14] D. A. Haines and G. H. Updike, Fire Whirlwind Formation over Flat Terrain, USDA Forest Service, North Central Forest Experiment Station, 1971.

[15] M. Umscheid, J. Monteverdi, and J. Davies, "Photographs and analysis of an unusually large and long-lived firewhirl," Severe Storms Meteorology, vol. 1, pp. 1-13, 2006. 
[16] P. Billing and R. Rawson, A Fire Tornado in the Sunset Country, Forests Commission, Victoria, Australia, 1982.

[17] D. J. McRae and M. D. Flannigan, "Development of large vortices on prescribed fires," Canadian Journal of Forest Research, vol. 20, no. 12, pp. 1878-1887, 1990.

[18] R. I. Emori and K. Saito, "Model experiment of hazardous forest fire whirl," Fire Technology, vol. 18, no. 4, pp. 319-327, 1982.

[19] US Bureau of Land Management, "Preliminary 72 Hour Briefing on Fish Fire Deployment Investigation," March 2010.

[20] US Bureau of Land Management, "New York Peak Fire Burnover, Factual Report," March 2010.

[21] C. Church, J. Snow, and J. Dessens, "Intense atmospheric vortices associated with a $1000 \mathrm{MW}$ fire," Bulletin American Meteorological Society, vol. 61, pp. 682-694, 1980.

[22] J. Dessens, "Man-made tornadoes," Nature, vol. 193, no. 4810, pp. 13-14, 1962.

[23] R. Zhou and Z. N. Wu, "Fire whirls due to surrounding flame sources and the influence of the rotation speed on the flame height," Journal of Fluid Mechanics, vol. 583, pp. 313-345, 2007.

[24] A. Y. Snegirev, J. A. Marsden, J. Francis, and G. M. Makhviladze, "Numerical studies and experimental observations of whirling flames," International Journal of Heat and Mass Transfer, vol. 47, no. 12-13, pp. 2523-2539, 2004.

[25] K. H. Chuah and G. Kushida, "The prediction of flame heights and flame shapes of small fire whirls," Proceedings of the Combustion Institute, vol. 31, pp. 2599-2606, 2007.

[26] K. H. Chuah, K. Kuwana, and K. Saito, "Modeling a fire whirl generated over a 5-cm-diameter methanol pool fire," Combustion and Flame, vol. 156, no. 9, pp. 1828-1833, 2009.

[27] D. G. Akhmetov, N. V. Gavrilov, and V. V. Nikulin, "Flow structure in a fire tornado-like vortex," Doklady Physics, vol. 52, no. 11, pp. 592-595, 2007.

[28] N. A. Chigier, J. M. Beér, D. Grecov, and K. Bassindale, "Jet flames in rotating flow fields," Combustion and Flame, vol. 14, no. 2, pp. 171-179, 1970.

[29] J. M. Beér, N. A. Chigier, T. W. Davies, and K. Bassindale, "Laminarization of turbulent flames in rotating environments," Combustion and Flame, vol. 16, no. 1, pp. 39-45, 1971.

[30] A. Muraszew, J. B. Fedele, and W. C. Kuby, "The fire whirl phenomenon," Combustion and Flame, vol. 34, pp. 29-45, 1979.

[31] G. M. Byram and R. E. Martin, "Fire whirlwinds in the laboratory," Fire Control Notes, vol. 33, pp. 13-17, 1962.

[32] R. E. Martin, D. W. Pendleton, and W. Burgess, "Effect of fire whirlwind formation on solid fuel burning rates," Fire Technology, vol. 12, no. 1, pp. 33-40, 1976.

[33] S. Soma and K. Saito, "Reconstruction of fire whirls using scale models," Combustion and Flame, vol. 86, no. 3, pp. 269-284, 1991.

[34] A. M. Grishin, A. N. Golovanov, and Y. V. Sukov, "Physical modeling of firestorms," Doklady Physics, vol. 49, no. 3, pp. 191-193, 2004.

[35] A. M. Grishin, A. N. Golovanov, A. A. Kolesnikov, A. A. Strokatov, and R. S. Tsvyk, "Experimental study of thermal and fire tornados," Doklady Physics, vol. 50, no. 2, pp. 66-68, 2005.

[36] K. Kuwana, K. Sekimoto, K. Saito, and F. A. Williams, "Scaling fire whirls," Fire Safety Journal, vol. 43, no. 4, pp. 252-257, 2008.

[37] S. L. Lee and F. W. Otto, "Gross vortex activities in a simple simulated urban fire," Symposium (International) on Combustion, vol. 15, no. 1, pp. 157-162, 1975.
[38] M. A. Jenkins, T. Clark, and J. Coen, "Coupling atmospheric and fire models," in Forest Fires: Behavior and Ecological Effects, E. A. Johnson and K. Miyanishi, Eds., 2001.

[39] A. M. Grishin, "Effect of the interaction between fire tornadoes on their propagation," Doklady Physics, vol. 52, no. 10, pp. 521-522, 2007.

[40] K. Kuwana, K. Sekimoto, K. Saito, F. A. Williams, Y. Hayashi, and H. Masuda, "Can we predict the occurrence of extreme fire whirls?" AIAA Journal, vol. 45, no. 1, pp. 16-19, 2007.

[41] R. N. Meroney, "Fire whirls and building aerodynamics," in Proceedings of the 11th International Conference on Wind Engineering, 2003.

[42] R. N. Meroney, "Fire whirls, fire tornados, and fire storms: physical and numerical modeling," in Proceedings of International Workshop on Physical Modelling of Flow and Dispersion Phenomena (PHYSMOD '03), Prato, Italy, 2003.

[43] S. Komurasaki, T. Kawamura, and K. Kuwahara, "Formation of a fire tornado and its breakdown," in Proceedings of the 48th Japan National Congress on Theoretical and Applied Mechanics (NCTAM '99), pp. 331-338, January 1999.

[44] F. Battaglia, K. B. McGrattan, R. G. Rehm, and H. R. Baum, "Simulating fire whirls," Combustion Theory and Modelling, vol. 4, no. 2, pp. 123-138, 2000.

[45] P. Cunningham, S. L. Goodrick, M. Y. Hussaini, and R. R. Linn, "Coherent vortical structures in numerical simulations of buoyant plumes from wildland fires," International Journal of Wildland Fire, vol. 14, no. 1, pp. 61-75, 2005.

[46] J. M. McDonough and A. Loh, "Simulation of vorticitybuoyancy interactions in fire-whirl-like phenomena," in Proceedings of the ASME Summer Heat Transfer Conference (HT '03), pp. 195-201, ASME, Las Vegas, Nev, USA, 2003.

[47] B. Morton, "Geophysical vortices," Progress in Aerospace Sciences, vol. 7, pp. 145-194, 1966.

[48] C. M. Countryman, Mass Fires and Fire Behavior, USDA Forest Service, Pacific Southwest Forest and Range Experiment Station, Berkeley, Calif, USA, 1964.

[49] C. M. Countryman, Fire Whirls...Why, When, and Where, USFS Pacific Southwest Research Station, Berkeley, Calif, USA, 1971.

[50] C. B. Clements, S. Zhong, X. Bian, W. E. Heidman, and D. W. Byun, "First observations of turbulence generated by grass fires," Journal of Geophysical Research D, vol. 113, no. 22, Article ID D22102, 2008.

[51] H. McMahon, D. Hester, and J. Palfrey, "Vortex shedding from a turbulent jet in a cross-wind," Journal of Fluid Mechanics, vol. 48, pp. 73-80, 1971.

[52] Z. M. Moussa, J. W. Trischka, and S. Eskinazi, "The near field in the mixing of a round jet with a cross-flow," Journal of Fluid Mechanics, vol. 80, no. 1, pp. 49-80, 1977.

[53] T. F. Fric and A. Roshko, "Vortical structure in the wake of a transverse jet," Journal of Fluid Mechanics, vol. 279, pp. 1-47, 1994.

[54] R. A. Brown, "Longitudinal instabilities and secondary flows in the planetary boundary layer: a review," Reviews of Geophysics \& Space Physics, vol. 18, no. 3, pp. 683-697, 1980.

[55] D. Etling and R. A. Brown, "Roll vortices in the planetary boundary layer: a review," Boundary-Layer Meteorology, vol. 65, no. 3, pp. 215-248, 1993.

[56] H. J. S. Fernando and D. C. Smith, "Vortex structures in geophysical convection," European Journal of Mechanics B, vol. 20, no. 4, pp. 437-470, 2001.

[57] J. Kuettner, "Cloud bands in the atmosphere," Tellus, vol. 23, pp. 404-425, 1971. 
[58] D. A. Haines and M. C. Smith, "Three types of horizontal vortices observed in wildland mass and crown fires," Journal of Climate \& Applied Meteorology, vol. 26, no. 12, pp. 1624-1637, 1987.

[59] S. C. P. Cheung and G. H. Yeoh, "A fully-coupled simulation of vortical structures in a large-scale buoyant pool fire," International Journal of Thermal Sciences, vol. 48, no. 12, pp. 2187-2202, 2009.

[60] B. M. Cetegen and T. A. Ahmed, "Experiments on the periodic instability of buoyant plumes and pool fires," Combustion and Flame, vol. 93, no. 1-2, pp. 157-184, 1993.

[61] V. Schaefer, "The relationship of jet streams to forest fires," Journal of Forestry, vol. 55, pp. 419-425, 1957.

[62] D. A. Haines, "Horizontal roll vortices and crown fires," Journal of Applied Meteorology, vol. 21, no. 6, pp. 751-763, 1982.

[63] W. Heilman and J. Fast, "Simulations of horizontal roll vortex development above lines of extreme surface heating," International Journal of Wildland Fire, vol. 2, pp. 55-68, 1992.

[64] D. A. Haines and M. Smith, "Simulation of the collapse of bent-over vortex pairs observed in wildland fires," Forest Science, vol. 38, pp. 68-79, 1992.

[65] J. Turner, "A comparison between buoyant vortex rings and vortex pairs," Journal of Fluid Mechanics, vol. 7, pp. 419-433, 1960.

[66] R. Scorer, Air Pollution, Pergamon Press, 1968.

[67] "La Convection atmosphérique et sa simulation," March 2011, http://www.cerimes.fr/le-catalogue/la-convectionatmospherique-et-sa-simulation.html.

[68] R. Margason, "Fifty years of jet in crossflow research," in Proceedings of the AGARD Symposium on Computational and Experimental Assessments of Jets in Crossflow, Advisory Group for Aerospace Research and Development, Winchester, UK, 1993.

[69] G. Tsang, "Laboratory study of two-dimensional starting plumes," Atmospheric Environment, vol. 4, no. 5, pp. 519-544, 1970.

[70] G. Tsang, "Laboratory study of line thermals," Atmospheric Environment, vol. 5, no. 7, pp. 445-471, 1971.

[71] M. C. Smith, D. A. Haines, and W. A. Main, "Some characteristics of longitudinal vortices produced by line-source heating in a low-speed wind tunnel," International Journal of Heat and Mass Transfer, vol. 29, no. 1, pp. 59-68, 1986.

[72] F. Luti, "Transient flow development due to a strong heatsource in the atmosphere. I. Uniform temperature source," Combustion Science and Technology, vol. 23, pp. 163-175, 1980.

[73] F. M. Luti, "Some characteristics of a two-dimensional starting mass fire with cross flow," Combustion Science and Technology, vol. 26, no. 1-2, pp. 25-33, 1981.

[74] B. Porterie, J. C. Loraud, D. Morvan, and M. Larini, "A numerical study of buoyant flow in cross-flow conditions," International Journal of Wildland Fire, vol. 9, no. 2, pp. 101$108,2000$.

[75] X. Zhang and A. F. Ghoniem, "A computational model for the rise and dispersion of wind-blown, buoyancy-driven plumes-I. Neutrally stratified atmosphere," Atmospheric Environment-Part A, vol. 27, no. 15, pp. 2295-2311, 1993.

[76] K. B. McGrattan, H. R. Baum, and R. G. Rehm, "Numerical simulation of smoke plumes from large oil fires," Atmospheric Environment, vol. 30, no. 24, pp. 4125-4136, 1996.

[77] J. Trelles, K. B. McGrattan, and H. R. Baum, "Smoke transport by sheared winds," Combustion Theory and Modelling, vol. 3, no. 2, pp. 323-341, 1999.
[78] G. M. Byram, Atmospheric Conditions Related to Blowup Fires, Southeast Forest Experiment Station, Asheville, NC, USA, 1954.

[79] T. L. Clark, M. A. Jenkins, J. Coen, and D. Packham, "A coupled atmosphere-fire model: convective feedback on fireLine dynamics," Journal of Applied Meteorology, vol. 35, no. 6, pp. 875-901, 1996. 

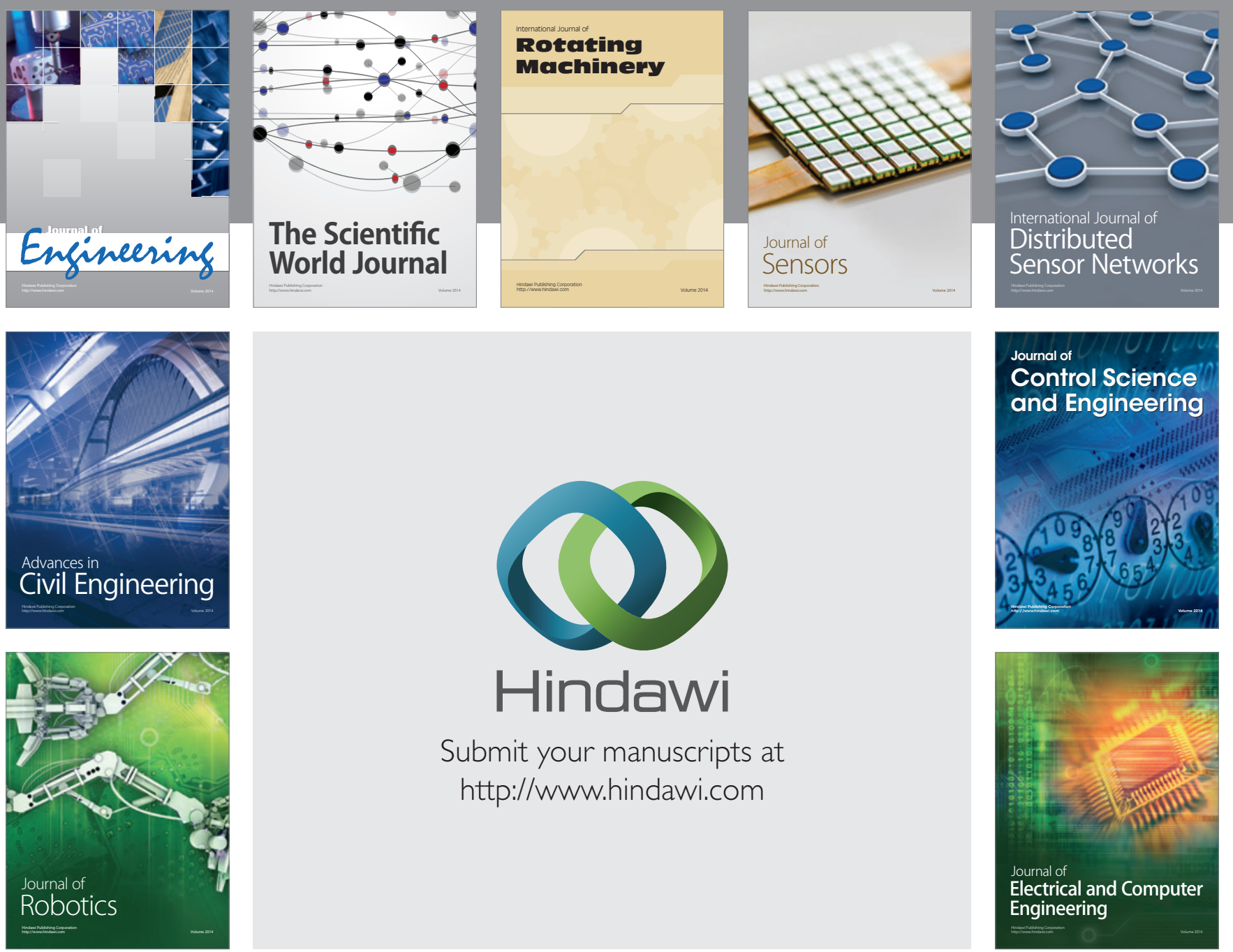

Submit your manuscripts at

http://www.hindawi.com
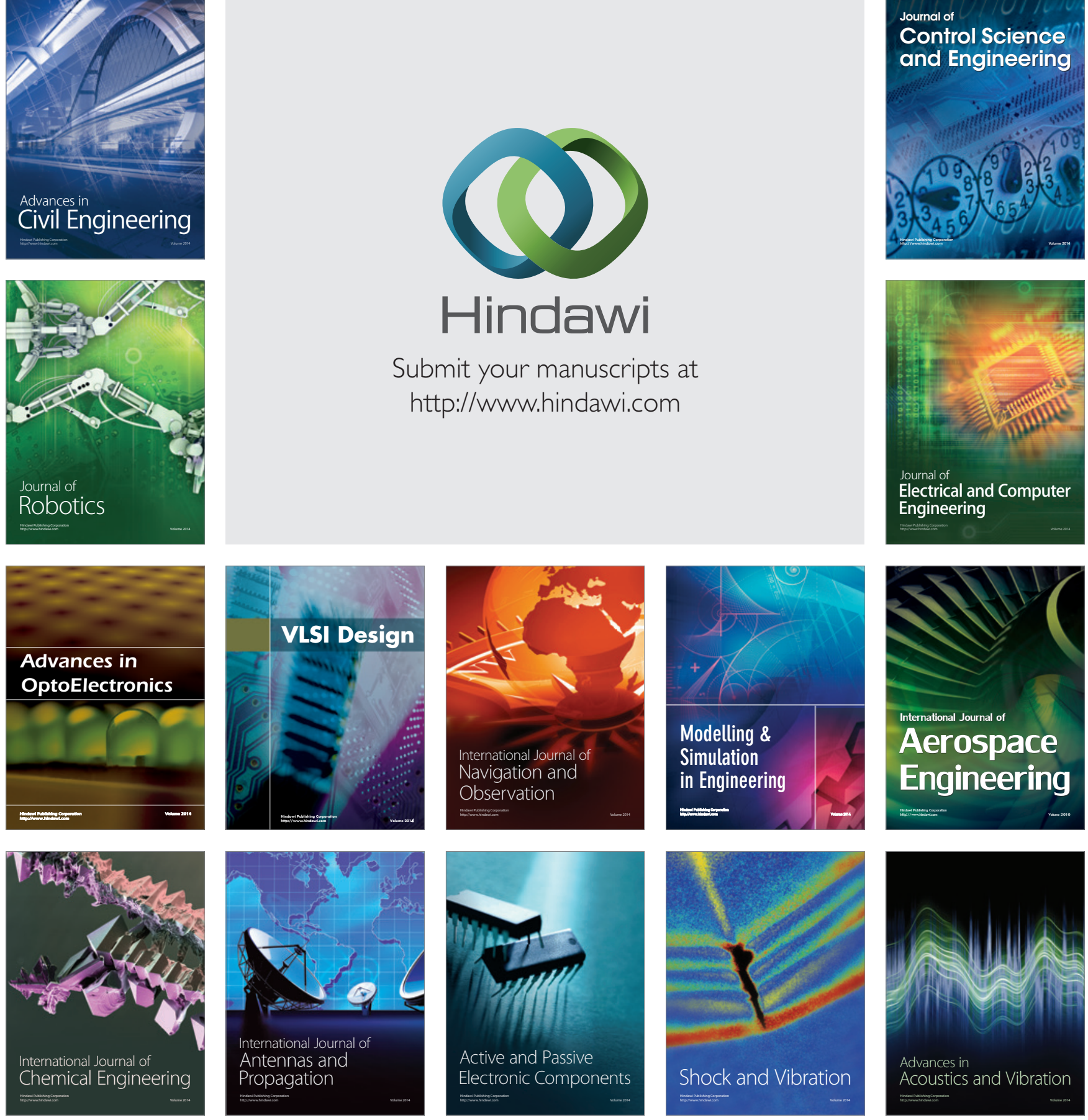